Forum 2018 · 33:294

https://doi.org/10.1007/s12312-018-0436-x

Online publiziert: 26. Juni 2018

(c) Springer Medizin Verlag $\mathrm{GmbH}$, ein Teil von Springer Nature 2018

BREMER

KREBSGesellschaft e.V.

Bremer Krebsgesellschaft e.V.

Bremen, Deutschland

\title{
Wechsel an der Vorstandsspitze
}

\author{
Prof. E.-H. Schmidt übergibt sein Amt an \\ Prof. H. Wenk
}

Auf der Mitgliederversammlung der Bremer Krebsgesellschaft e.V. am 16. Mai 2018 gab Prof. Ernst Heinrich Schmidt bekannt, dass er sein mehr als 30 Jahre lang ausgeübtes Amt als Vorsitzender des Vereins künftig in andere Hände legen möchte. Während der Sitzung skizzierte er noch einmal die Entwicklung der Bremer Krebsgesellschaft, die in seiner Amtszeit von damals 60 Mitgliedern auf fast 1000 Mitglieder angewachsen ist und heute ein vielseitiges und stetig wachsendes Angebot für Menschen mit Krebs und ihre Angehörigen bereit hält.

Einstimmig zum neuen Vorsitzenden gewählt wurde Prof. Dr. Heiner Wenk, Direktor der Klinik für Allgemein, Gefäß und Visceralchirurgie am Klinikum Bremen-Nord, der die Geschicke des Vereins bereits lange Jahre als zweiter Vorsitzender mit gelenkt hat. Dieses Amt übernimmt ab sofort der niedergelassene Urologe Dr. Reinhard Hübotter, ebenfalls langjähriges Vorstandsmitglied; auch er erhielt keine Gegenstimme.

Als Würdigung seines langjährigen Engagements und seiner Verdienste um die Bremer Krebsgesellschaft wurde Professor Schmidt abschließend zu ihrem Ehrenvorsitzenden auf Lebenszeit ernannt.

\section{Korrespondenzadresse}

\section{Marie Rösler}

Bremer Krebsgesellschaft e.V.

Am Schwarzen Meer 101-105, 28205 Bremen,

Deutschland

roesler@bremerkrebsgesellschaft.de

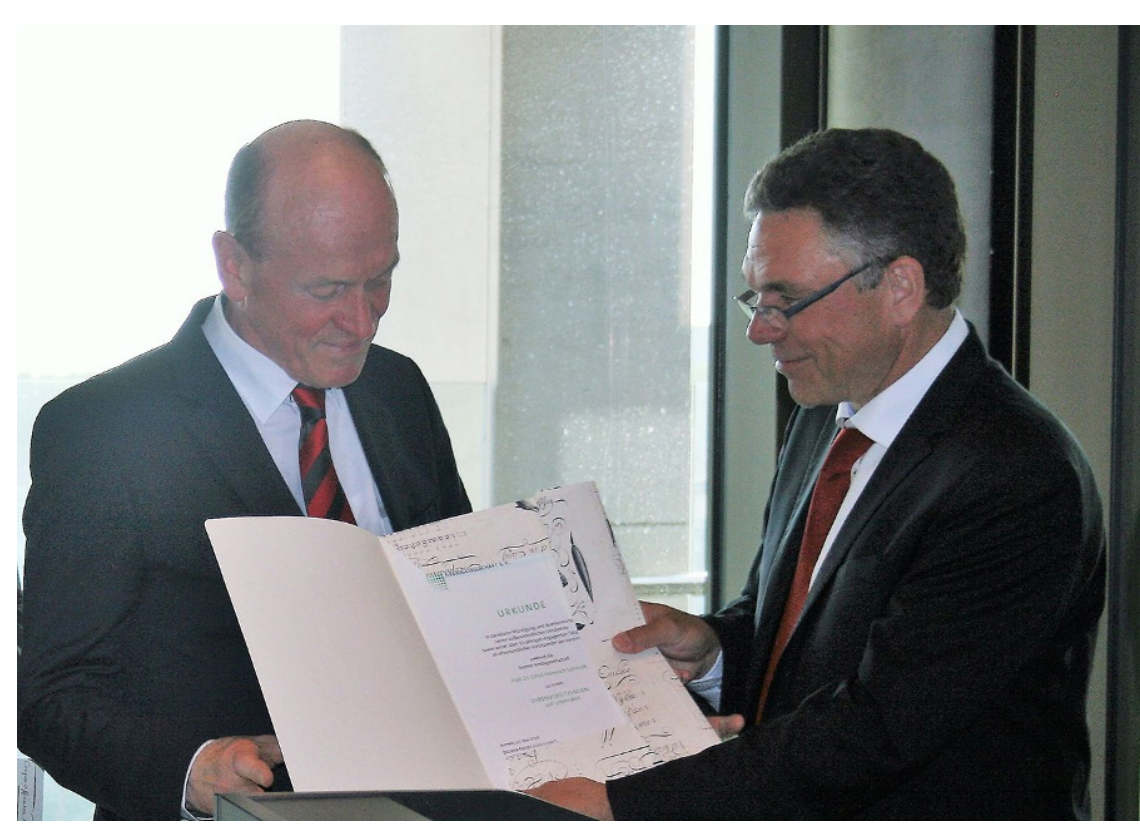

$\Delta$ Prof. Dr. Heiner Wenk, neuer Vorsitzender der Bremer Krebsgesellschaft (re) überreicht die Urkunde zum Ehrenvorsitzenden seinem Vorgänger Prof. Dr. H. Schmidt (li). @ Eva Riemann 